\title{
Evaluation of non-coding region sequence variants and mitochondrial haplogroups as potential biomarkers of sporadic breast cancer in individuals of Sri Lankan Sinhalese ethnicity
}

\author{
JOANNE TIPHANIA KOTELAWALA ${ }^{1}$, RUWANDI RANASINGHE ${ }^{1}$, CHRISHANI RODRIGO $^{1}$, \\ KAMANI HEMAMALA TENNEKOON ${ }^{1}$ and KANISHKA DE SILVA ${ }^{2}$ \\ ${ }^{1}$ Institute of Biochemistry, Molecular Biology and Biotechnology, University of Colombo, Colombo 00300; \\ ${ }^{2}$ National Cancer Institute, Apeksha Hospital, Maharagama 10280, Sri Lanka
}

Received September 20, 2019; Accepted January 30, 2020

DOI: $10.3892 /$ br.2020.1292

\begin{abstract}
Mitochondrial DNA (mtDNA) mutations have been reported to be associated with various diseases, including cancer. The present study investigated the mtDNA non-coding region mutations and mitochondrial haplogroups as potential biomarkers of sporadic breast cancer in Sri Lankan Sinhalese women. Mitochondrial macro-haplogroups were determined using PCR-restriction fragment length polymorphism, whereas non-coding region sequences were determined using Sanger sequencing. The sequence of the non-coding region was also used to confirm haplogroup status. Neither the mutations in the non-coding region nor the mitochondrial haplogroups that were reported as risk factors in other populations, were determined to be potential risk factors for sporadic breast cancer in the present study. Furthermore, several novel mutations were identified in the present matched pairs case-controlled study. The M65a haplogroup with an additional mutation at position $16311(\mathrm{P}=0.0771)$ and mutations at the ori-b site $(\mathrm{P}=0.05)$ were considered a weak risk factor and protective factor, respectively, for sporadic breast cancer in Sinhalese women. Previous studies have indicated the use of mtDNA mutations as a biomarker; however, the present study showed that such biomarkers need to be validated for individual ethnic groups
\end{abstract}

Correspondence to: Ms. Joanne Tiphania Kotelawala, Institute of Biochemistry, Molecular Biology and Biotechnology, University of Colombo, 90 Cumaratunga Munidasa Mawatha, Colombo 00300, Sri Lanka

E-mail: joanne.kotelawala@gmail.com

Abbreviations: BMI, body mass index; CSB, conserved sequence blocks; D-loop, displacement loop; H-strand, heavy strand; L-strand, light strand; mtDNA, mitochondrial DNA; RSRS, Reconstructed Sapiens Reference Sequence; rCRS, revised Cambridge Reference Sequence

Key words: mtDNA, breast cancer, Sri Lanka, M65a, control region, haplogroup before they can be recommended for use in the prediction of disease.

\section{Introduction}

Breast cancer remains one of the most common types of cancer diagnosed in women worldwide (1). In Sri Lanka, breast cancer accounts for $\sim 25 \%$ of all diagnosed cancer cases in women and is the leading type of cancer in terms of incidence (2). Early diagnosis of breast cancer improves patient prognosis. Current detection methods are based on identification of signs or symptoms of a tumour by the patient or a clinician (3). However, the development of improved diagnostic tools, such as biomarkers, may aid in diagnosis prior to manifestation of any visible physical symptoms (4). Breast cancer can be inherited (familial breast cancer), in which a relative would have previously been diagnosed with breast cancer; or can occur in patients with no prior family history (sporadic breast cancer) (5). Sporadic and familial breast cancer account for 90-95 and 5-10\% of all breast cancer cases, respectively $(6,7)$.

Mitochondrial DNA (mtDNA) is stored in the mitochondrial matrix, and codes for components of the electron transport chain that controls cellular respiration (8). Each mitochondrion has multiple copies of mtDNA and each cell has several mitochondria $(8,9)$. mtDNA is a double-stranded, circular structure that is $16,569 \mathrm{bp}$ in length (8). The double strand consists of a heavier $(\mathrm{H})$ and a lighter $(\mathrm{L})$-strand (8). mtDNA consists of two regions: A non-coding and a coding region. The non-coding region, also known as the displacement loop (D-loop), is $\sim 1,500$ bp in length and is a short triple-stranded structure, in which a short strand of 7S DNA displaces the $\mathrm{H}$-strand $(10,11)$. The D-loop serves an important role in the replication and transcription of mtDNA as it contains the sites of replication initiation and promoters for the transcription of downstream genes $(8,10)$. Alterations in the mitochondrial genome are associated with a number of chronic diseases such as diabetes, Leber hereditary optic neuropathy, metabolic diseases as well as several types of cancer $(10,12-14)$.

According to the Warburg hypothesis, cancer is a metabolic disease caused by mitochondrial damage (15). A biomarker is typically a molecule that can indicate a disease condition or 
predict the risk of developing a particular disease, including cancer (16). Certain biomarkers are widely used in clinical practice to determine treatment options and the effectiveness of treatment $(17,18)$. Current biomarkers for breast cancer include the oestrogen and progesterone receptors, human epidermal growth factor receptor 2 and $\mathrm{Ki}-67$ status in the tumour tissue (18), as well as inherited mutations in genes, such as $B R C A 1$ and $B R C A 2$, which can be detected in the peripheral blood (17). Whilst the latter can predict the risk of inherited breast cancer (19), the former cannot be used to predict sporadic breast cancer but can inform treatment options (20). Therefore, there is an unmet need for the identification of circulating biomarkers that can predict the risk of sporadic breast cancer. mtDNA has been studied as a potential biomarker in assessing the risk of developing breast cancer in certain populations $(21,22)$. The mitochondrial D-loop region has been shown to be a hotspot of variations associated with breast cancer (23). In addition, mutations located between positions 303 and 315 are frequently observed in cancer (24). Germline mutations such as T16189C, T16519C and G10398A have been reported as risk factors in breast cancer, whereas variations such as T3197C and G13708A are reported to serve as protective factors in certain populations $(25,26)$. mtDNA is primarily inherited maternally and the mutational profile varies in different populations and ethnicities $(27,28)$. Previous studies have investigated the variations in the mitochondrial genome of patients in different populations $(26,29,30)$; however, to the best of our knowledge, there are no studies on Sri Lankan patients. Therefore, the present study was performed to evaluate whether germline mtDNA D-loop mutations and mitochondrial haplogroups are associated with sporadic breast cancer in Sri Lankan patients of Sinhalese ethnicity.

\section{Patients and methods}

Sample collection. The present study was approved by the Ethics Review Committee of the Faculty of Medicine, University of Colombo (approval no. EC-16-097). Patients of Sinhalese ethnicity $(n=63)$ with a confirmed diagnosis of breast cancer were recruited from the National Cancer Institute of Sri Lanka between November 2012 and January 2018. A peripheral venous blood sample was obtained from the patients prior to chemotherapy or hormonal therapy and demographic and clinical data were collected after obtaining written informed consent. As the control group, healthy Sinhalese women $(n=63)$ matched for age, body mass index (BMI) and menopausal status were recruited from the community after obtaining written informed consent. The controls did not have any family or personal history of cancer or acute or chronic illness. Patients and controls were aged 28-76 years (mean \pm standard deviation, $50.683 \pm 10.715$ and $50 \pm 10.682$ years, respectively).

DNA extraction and quantification. Genomic DNA from each sample was extracted using a modified version of Miller's salting out procedure, as described previously (31). The DNA quality and quantity were assessed using a BioSpec Nano spectrophotometer (Shimadzu Corporation).

Control region amplification. DNA extracted from the patients and the controls were amplified using PCR. The primers used in the present study were previously described by Reider et al (32) and the sequences were: 23-forward, 5'-TCATTGGACAAGTAGCATCC-3' and reverse, 5'-GAG TGGTTAATAGGGTGATAG-3'; and 24-forward, 5'-CAC CATCCTCCGTGAAATCA-3' and reverse, 5'-AGGCTAAGC GTTTTGAGCTG-3'. The primers were used to amplify the 1,500 bp control region as two separate PCR products. The PCR mix contained 50 ng DNA, $1.5 \mathrm{mM} \mathrm{MgCl} \mathrm{Mg}_{2}$, 1x Green GoTaq $^{\circledR}(10 \mathrm{mM}$ Tris-HCl; pH 8.3 and $50 \mathrm{mM} \mathrm{KCl}$ ) (Promega Corporation), $0.2 \mathrm{mM}$ dNTPs, (Promega Corporation), $0.2 \mu \mathrm{M}$ of each primer (Integrated DNA technologies), 1.5 units GoTaq ${ }^{\circledR}$ Flexi DNA polymerase (Promega Corporation) and $0.16 \mathrm{mg} / \mathrm{ml}$ acetylated BSA (Promega Corporation). The PCR mix was prepared to a final volume of $25 \mu 1$. PCR was performed in a Veriti Thermal Cycler (Thermo Fisher Scientific, Inc.) with the following thermocycling conditions: $94^{\circ} \mathrm{C}$ for $5 \mathrm{~min}$; followed by 38 cycles of $94^{\circ} \mathrm{C}$ for $1 \mathrm{~min}$, optimised annealing temperature of $61^{\circ} \mathrm{C}$ for $1 \mathrm{~min}, 72^{\circ} \mathrm{C}$ for $2 \mathrm{~min}$; with a final extension step of $72^{\circ} \mathrm{C}$ for $10 \mathrm{~min}$. The PCR products were purified using a Wizard ${ }^{\circledR} \mathrm{SV}$ Gel and PCR Clean-Up kit (Promega Corporation). The sequence of the amplified region was determined using Sanger sequencing. The samples were sequenced using a BigDye ${ }^{\circledR}$ Terminator v3.1 cycle sequencing kit (Thermo Fisher Scientific, Inc.) and sequencing products were run on an Applied Biosystems 3500Dx Genetic Analyzer (Thermo Fisher Scientific, Inc.). The sequences were analysed using Mutation Surveyor ${ }^{\circledR}$ (version 4.09; SoftGenetics ${ }^{\circledR}$ ), with the revised Cambridge Reference Sequence (rCRS; GenBank accession number NC_012920.01) as the reference. Subsequently, the data were analysed using the Reconstructed Sapiens Reference Sequence (RSRS) (33) and mutations at the genomic level were identified.

Haplogroup and haplotype assessment. The $\mathrm{M}$ and $\mathrm{N}$ macro-haplogroup status of the samples was determined using PCR-restriction fragment length polymorphism (RFLP). The coding regions were amplified by PCR using primers described in a previous study (34). The primer sequences were: 10,279 forward, 5'-CCCTACCATGAGCCCTACAA-3'; 10,485 reverse, 5'-TGTAAATGAGGGGCATTTGG-3'); 10,687 forward, 5'-TGG GCCTAGCCCTACTAGTCT-3'; and 10,931 reverse, 5'-AGG AAAAGGTTGGGGAACAG-3'. The PCR products were digested using the restriction enzymes $A l u \mathrm{I}$ and $M n l \mathrm{I}$ as described by Ranasinghe (34). The D-loop region nucleotide sequences were used to assign haplogroups to each sample. Mutations associated with individual samples were analysed using HaploGrep version 2.2 (35), EmPop mtDNA database version 4.0 (36) and validated using PhyloTree build 17 (37). The haplotypes were determined by manually searching for grouped mutations.

Statistical analysis. Statistical analysis was performed using GraphPad QuickCalcs (38). A McNemar's test was used to compare the prevalence of haplotypes and mutations between the patients and the controls. $\mathrm{P}<0.05$ was considered to indicate a statistically significant difference.

\section{Results}

Clinicopathological characteristics of the patients and controls. In the present study, 63 patients with sporadic breast 
Table I. Clinicopathological characteristics of patients and matched controls.

A, Matched pairs, $n=63$

\begin{tabular}{lcc}
\hline Age, years & $\mathrm{n}$ & Percentage \\
$20-29$ & 1 & 1.59 \\
$30-39$ & 10 & 15.87 \\
$40-49$ & 16 & 25.40 \\
$50-59$ & 20 & 31.75 \\
$60-69$ & 14 & 22.22 \\
$70-79$ & 2 & 3.17 \\
Menopausal status & & \\
Premenopausal & 30 & 47.62 \\
Post-menopausal & 33 & 52.38 \\
BMI & & \\
Underweight $(<18.5)$ & 4 & 6.35 \\
Normal (18.5-24.9) & 30 & 47.62 \\
Overweight $(25.0-29.9)$ & 21 & 33.33 \\
Obese (>30) & 8 & 12.70 \\
\hline
\end{tabular}

B, Patients, $n=63$

\begin{tabular}{lrr}
\hline Ductal carcinoma & 42 & 66.67 \\
In situ & 5 & \\
Invasive/infiltrating & 34 & \\
Only classified as ductal carcinoma & 3 & \\
Lobular carcinoma & 7 & 11.11 \\
In situ & 1 & \\
Invasive/infiltrating & 5 & \\
Only classified as lobular carcinoma & 1 & \\
Carcinoma of no specific type & 8 & 12.70 \\
Grade 2a & 6 & \\
Grade $1^{\text {a }}$ & 1 & \\
No known grade & 1 & \\
Mucinous carcinoma & 1 & 1.59 \\
Invasive squamous carcinoma & 1 & 1.59 \\
Invasive adenocarcinoma & 1 & 1.59 \\
Adenoid cystic carcinoma & 1 & 1.59 \\
Papillary carcinoma & 2 & 3.17 \\
\hline
\end{tabular}

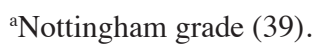

cancer were recruited, as well as 63 age, BMI and menopausal status matched controls. The majority of the patients and controls $(31.75 \%)$ belonged to the 50-59 years age category, in addition, $52.38 \%$ of the patients and controls were post-menopausal, whereas $47.62 \%$ were pre-menopausal. A majority $(47.62 \%)$ had a BMI considered normal, whereas $33.33 \%$ were classified as overweight. There were no differences between the patients and healthy control groups. Amongst the patients, ductal carcinoma was predominant $(66.67 \%)$ while lobular carcinoma accounted for $11.11 \%$. Carcinoma of no specific type and grade were classified according to the Nottingham grade of the tumour (39). The clinicopathological
Table II. Mutations observed in $>5 \%$ of either sporadic breast cancer patients or controls.

\begin{tabular}{|c|c|c|c|c|}
\hline \multirow{2}{*}{$\begin{array}{l}\text { Mutation, } \\
\text { reference, rCRS }\end{array}$} & \multicolumn{2}{|c|}{ Patients, $\mathrm{n}=63$} & \multicolumn{2}{|c|}{ Controls, $\mathrm{n}=63$} \\
\hline & $\mathrm{N}$ & $\%$ & $\mathrm{~N}$ & $\%$ \\
\hline A73G & 60 & 95.24 & 61 & 96.83 \\
\hline $\mathrm{T} 146 \mathrm{C}$ & 10 & 15.87 & 10 & 15.87 \\
\hline $\mathrm{C} 150 \mathrm{~T}$ & 12 & 19.04 & 7 & 11.11 \\
\hline $\mathrm{C} 151 \mathrm{~T}$ & 3 & 4.76 & 5 & 7.94 \\
\hline $\mathrm{T} 152 \mathrm{C}$ & 17 & 26.98 & 20 & 31.75 \\
\hline A153G & 1 & 1.59 & 3 & 4.76 \\
\hline $\mathrm{T} 195 \mathrm{C}$ & 13 & 20.64 & 16 & 25.40 \\
\hline T199C & 4 & 6.35 & 4 & 6.35 \\
\hline T204C & 5 & 7.94 & 4 & 6.35 \\
\hline A234G & 3 & 4.76 & 7 & 11.11 \\
\hline A240G & 1 & 1.59 & 4 & 6.35 \\
\hline A263G & 59 & 93.65 & 63 & 100 \\
\hline 309insC & 17 & 26.98 & 21 & 33.3 \\
\hline 309insCC & 4 & 6.35 & 5 & 7.94 \\
\hline T310C & 3 & 4.76 & 6 & 9.52 \\
\hline 315 insC & 47 & 74.6 & 52 & 82.54 \\
\hline 315 insCC & 4 & 6.35 & 2 & 3.17 \\
\hline $\mathrm{C} 447 \mathrm{G}$ & 5 & 7.93 & 3 & 4.76 \\
\hline $\mathrm{T} 482 \mathrm{C}$ & 4 & 6.35 & 7 & 11.11 \\
\hline T489C & 33 & 52.4 & 37 & 58.73 \\
\hline $\mathrm{C} 511 \mathrm{~T}$ & 8 & 12.7 & 2 & 3.17 \\
\hline 523_524delAC & 14 & 22.22 & 22 & 34.92 \\
\hline A16051G & 7 & 11.11 & 8 & 12.7 \\
\hline T16093A & 7 & 11.11 & 2 & 3.17 \\
\hline $\mathrm{T} 16093 \mathrm{C}$ & 3 & 4.76 & 8 & 12.7 \\
\hline $\mathrm{T} 16126 \mathrm{C}$ & 1 & 1.59 & 5 & 7.93 \\
\hline $\mathrm{T} 16172 \mathrm{C}$ & 3 & 4.76 & 7 & 11.11 \\
\hline A16183C & 3 & 4.76 & 4 & 6.35 \\
\hline C16193T & 1 & 1.59 & 5 & 7.93 \\
\hline 16193dupC & 2 & 3.17 & 4 & 6.35 \\
\hline T16209C & 2 & 3.17 & 4 & 6.35 \\
\hline $\mathrm{T} 16231 \mathrm{C}$ & 2 & 3.17 & 4 & 6.35 \\
\hline G16274A & 8 & 12.7 & 4 & 6.35 \\
\hline A16289G & 7 & 11.11 & 1 & 1.59 \\
\hline T16304C & 6 & 9.52 & 3 & 4.76 \\
\hline A16318T & 3 & 4.76 & 4 & 6.35 \\
\hline G16319A & 11 & 17.46 & 6 & 7.23 \\
\hline C16320T & 4 & 6.35 & 3 & 4.76 \\
\hline $\mathrm{T} 16352 \mathrm{C}$ & 4 & 6.35 & 5 & 7.94 \\
\hline C16353T & 2 & 3.17 & 4 & 6.35 \\
\hline T16356C & 4 & 6.35 & 3 & 4.76 \\
\hline T16362C & 6 & 9.52 & 12 & 19.05 \\
\hline T16519C & 53 & 84.13 & 52 & 82.53 \\
\hline
\end{tabular}

rCRS, revised Cambridge reference sequence.

characteristics of the matched patients and controls are presented in Table I. 
Table III. Mutations identified in regions important for replication and transcription in sporadic breast cancer patients and matched controls.

\section{A, Replication}

\begin{tabular}{|c|c|c|c|c|c|}
\hline \multirow[b]{2}{*}{ Location } & \multirow[b]{2}{*}{ Function } & \multirow{2}{*}{$\begin{array}{l}\text { Nucleotide position } \\
\text { of binding site }\end{array}$} & \multirow{2}{*}{$\begin{array}{l}\text { Mutations identified } \\
\text { in these regions }\end{array}$} & \multicolumn{2}{|c|}{ Occurrence } \\
\hline & & & & Patients & Controls \\
\hline \multirow[t]{4}{*}{ Heavy strand } & Origin of replication $\left(\mathrm{O}_{\mathrm{H}}\right)$ & 57 & $\begin{array}{l}\text { 56del, A56T, T57A, T58A, 65TTins, } \\
\text { G66T }\end{array}$ & 0 & 2 \\
\hline & & 191 & $\begin{array}{l}\text { C182T, G185A, C186T, A189G, } \\
\text { C194T, T195C, T195A, C198T, } \\
\text { T199C, A200G }\end{array}$ & 27 & 28 \\
\hline & & 300 & A297G, 301CCins & 0 & 4 \\
\hline & Second origin (Ori-b) & 16197 & $\begin{array}{l}\text { C16187T, 16187CCdup, C16188T, } \\
\text { C16192T, C16193T, 16193CCdup, } \\
\text { A16206C, A16207G }\end{array}$ & 19 & 32 \\
\hline
\end{tabular}

B, Transcription

\begin{tabular}{|c|c|c|c|c|c|}
\hline \multirow[b]{2}{*}{ Location } & \multirow[b]{2}{*}{ Function } & \multirow{2}{*}{$\begin{array}{l}\text { Nucleotide position } \\
\text { of binding site }\end{array}$} & \multirow{2}{*}{$\begin{array}{l}\text { Mutations identified } \\
\text { in these regions }\end{array}$} & \multicolumn{2}{|c|}{ Occurrence } \\
\hline & & & & Patients & Controls \\
\hline Heavy strand & Initiation $\left(\mathrm{IT}_{\mathrm{H} 1}\right)$ & 561 & 560_561CAdel & 1 & 0 \\
\hline Light strand & Promoter $\left(\mathrm{IT}_{\mathrm{L}}\right)$ & 408 & None & 0 & 0 \\
\hline- & mtRNAP/TFB2M footprint & $546-570$ & 560_561CAdel, T569C & 3 & 0 \\
\hline- & TFAM footprint & $520-545$ & 523dupAC, 523_524ACdel & 15 & 22 \\
\hline- & $\begin{array}{l}\text { Region required for } \\
\text { promoter activity }\end{array}$ & $520-531$ & 523dupAC, 523_524ACdel & 15 & 22 \\
\hline
\end{tabular}

TFAM, transcription factor A; mtRNAP, mitochondrial RNA polymerase; TFB2M, transcription factor B2.

D-loop variations. Mitochondrial D loop sequences in 63 patients with histologically confirmed sporadic breast cancer were analysed according to their age, BMI and menopausal status against the matched controls. The samples displayed a total mutational profile as follows: 680 and 733 mutations in the patients and controls, respectively, when analysed using the rCRS. There were 395 and 426 mutations in the patients and controls, respectively, when analysed using the RSRS. Mutations that were present in $>5 \%$ of either patients or controls are presented in Table II.

The mtDNA hyper-variable regions are hotspots of genetic variation compared with the rest of the D-loop region (40). The data collected in the present study were used to compare the mutational profile obtained with rCRS in the three hyper-variable regions. There were 221 and 234 mutations within hypervariable region I, 293 and 319 mutations within hypervariable region II; and 77 and 84 mutations within hypervariable region III in the patients and the controls, respectively. Certain mutations were observed in significant areas of the non-coding region, such as the origin of replication for the $\mathrm{H}$ strand, $\mathrm{H}$ and $\mathrm{L}$ strand promoter regions and transcription initiation sites (Table III). Mutations at the ori-b site in the heavy strand were seen in 32 controls and 19 patients
$[\mathrm{P}=0.05$; odds ratio $(\mathrm{OR}), 0.517 ; 95 \%$ confidence interval $(\mathrm{CI})$, $0.258-0.997]$. The difference in the prevalence of mutations in the mitochondrial transcription factor A (TFAM) footprint and the region required for promoter activity between the patients and the controls was not statistically significant $(\mathrm{P}=0.2012$; OR, 0.579; 95\% CI, 0.249-1.280 for both). Although a number of mutations reported to be associated with breast cancer in other populations were observed in the present study, their prevalence was not significantly different between the patients and the controls (Table IV).

Mutations at the site of transcription initiation in the heavy strand $\left(\mathrm{IT}_{\mathrm{H} 1}\right)$ and the site containing the footprint of mitochondrial RNA polymerase (mtRNAP)/mitochondrial transcription factor B2 (TFB2M) binding $(41,42)$ were seen in three patients (patient codes: B10, B51 and B03). Patient B03 was 37 years old with a BMI of 16.9 , menarche at 13 years and gave birth to a child at the age of 29. The patient had no history of miscarriages and has previously used hormonal contraceptives. The patient was diagnosed with ductal carcinoma in situ (Nottingham grade 2) and underwent a lumpectomy. The other two patients were diagnosed at a later stage of the disease. Patient B10 was 51 years old with a BMI of 26.8, menarche at 11 years and gave birth to a child at the age of 16 . The patient had experienced a 
Table IV. Prevalence of mitochondrial D loop mutations reported to be associated with breast cancer in other populations compared with the present study.

\begin{tabular}{|c|c|c|c|c|c|c|}
\hline Author, year & Mutation & Patients, $n$ & Controls, $\mathrm{n}$ & $\begin{array}{l}\text { Ethnicity of } \\
\text { patients in } \\
\text { the study }\end{array}$ & Description & (Refs.) \\
\hline Cai et al, 2011 & A73G & 60 & 61 & Chinese & Germline & (21) \\
\hline Czarnecka et al, 2010 & & & & Polish & Germline, primary breast cancer & $(52)$ \\
\hline Cai et al, 2011 & $\mathrm{C} 150 \mathrm{~T}$ & 12 & 7 & Chinese & Germline & (21) \\
\hline Cai et al, 2011 & $\mathrm{~T} 217 \mathrm{C}$ & 2 & 0 & Chinese & Germline & $(21)$ \\
\hline Czarnecka et al, 2010 & $\mathrm{~T} 239 \mathrm{C}$ & 1 & 1 & Polish & Germline, primary breast cancer & $(52)$ \\
\hline Czarnecka et al, 2010 & A263G & 59 & 63 & Polish & Germline, primary breast cancer & $(52)$ \\
\hline Tipirisetti et al, 2014 & $\begin{array}{l}310 \mathrm{C} \\
\text { insertion }\end{array}$ & 3 & 6 & South Indian & $\begin{array}{l}\text { Germline, primary breast cancer, } \\
\text { controls matched for age, sex } \\
\text { and ethnicity }\end{array}$ & (26) \\
\hline Tan et al, 2002 & A189G & 3 & 0 & American (USA) & Germline & (53) \\
\hline Cai et al, 2011 & T16126C & 1 & 5 & Chinese & Germline & (21) \\
\hline Wang et al, 2006 & T16189C & 11 & 17 & $\begin{array}{l}\text { Chinese } \\
\text { (Hong Kong) }\end{array}$ & Somatic, primary breast cancer & (24) \\
\hline Tipirisetti et al, 2014 & & & & South Indian & $\begin{array}{l}\text { Germline, primary breast cancer, } \\
\text { controls matched for age, sex } \\
\text { and ethnicity }\end{array}$ & (26) \\
\hline Cai et al, 2011 & & & & Chinese & Germline & $(21)$ \\
\hline Cai et al, 2011 & $\mathrm{~T} 16217 \mathrm{C}$ & 0 & 1 & Chinese & Germline & (21) \\
\hline Czarnecka et al, 2010 & A16207G & 0 & 1 & Polish & Germline, primary breast cancer & $(52)$ \\
\hline Cai et al, 2011 & T16266C & 2 & 3 & Chinese & Germline & (21) \\
\hline Bai et al, 2007 & $\mathrm{~T} 16519 \mathrm{C}$ & 53 & 52 & European-American & $\begin{array}{l}\text { Germline, Familial breast cancer, } \\
\text { controls matched for age and sex }\end{array}$ & $(25)$ \\
\hline
\end{tabular}

Table V. Distribution of macro-haplogroups $\mathrm{M}$ and $\mathrm{N}$ identified by PCR-restriction fragment length polymorphism and haplogroups identified using D-loop sequencing in patients with sporadic breast cancer patients and matched controls.

\begin{tabular}{lccr}
\hline Macro-haplogroup & Haplogroup & Patients, $\mathrm{n}$ & Controls, $\mathrm{n}$ \\
\hline $\mathrm{M}$ & $\mathrm{M}$ & 35 & 33 \\
& $\mathrm{D}$ & 1 & 2 \\
$\mathrm{~N}$ & Total & 36 & 35 \\
& $\mathrm{~N}$ & 1 & 1 \\
& $\mathrm{U}$ & 10 & 11 \\
& $\mathrm{R}$ & 10 & 11 \\
& $\mathrm{H}$ & 3 & 2 \\
& $\mathrm{~T}$ & 1 & 2 \\
& $\mathrm{~W}$ & 1 & 0 \\
& $\mathrm{P}$ & 1 & 0 \\
L & Total & 27 & 27 \\
Total & - & 0 & 1 \\
\hline
\end{tabular}

miscarriage and had no history of hormonal contraceptive use. The patient was diagnosed with invasive ductal carcinoma and underwent a mastectomy with level III axillary clearance and succumbed to the disease 10 weeks after clinical diagnosis. Patient B51 was 53 years old with a BMI of 30.5, menarche at 12 years, had experienced four miscarriages and received fertility treatment to conceive but had no children. The patient was diagnosed with invasive ductal carcinoma (Nottingham grade 2) and underwent a mastectomy and level III axillary clearance.

Haplogroup analysis. The macro-haplogroups identified in the patients and the controls using PCR-RFLP and the haplogroups predicted using the D-loop sequence mutations using HaploGrep, EmPop and validated with PhyloTree are presented in Table V. The M macro-haplogroup included haplogroups $\mathrm{M}$ and $\mathrm{D}$, whereas the rest of the haplogroups belonged to the $\mathrm{N}$ macro-haplogroup. The distribution of the macrohaplogroups and haplogroups among the patients and the controls was similar.

Analysis of the shared haplogroups showed that haplogroup M65a with an additional mutation at position 16311 (M65a@16311) was present in 7 patients and only in 1 control. However, when analysed using the McNemar test, the difference was not statistically significant $(\mathrm{P}=0.0771$; OR, 7.00; 95\% CI, 0.899-315.483). Haplogroup M65, which is the nearest root for haplogroup M65a, was observed in 
Table VI. Haplotypes observed in more than one sporadic breast cancer patient or matched control.

\begin{tabular}{llcc}
\hline Haplotype & \multicolumn{1}{c}{ Mutations } & Patients & Controls \\
\hline 1 & 73G, 150T, 195C, 240G, 263G, 315.1C, 16129A, 16266T, 16311C, 16318G, 16320T, & 0 & 2 \\
& 16362C, 16519C & & \\
2 & 73G, 195A, 263G, 315.1C, 489C, 523d, 524d, 16223T, 16519C & 1 & 2 \\
3 & 73G, 199C, 263G, 315.1C, 482C, 489C, 16093C, 16223T, 16519C & 1 & 2 \\
4 & 73G, 150T, 263G, 315.1C, 489C, 511T, 16223T, 16289G, 16519C & 4 & 0 \\
5 & 73G, 204C, 263G, 315.1C, 447G, 489C, 16223T, 16270T, 16274A, 16319A, 16352C, 16519C & 1 & 1 \\
6 & 73G, 195A, 263G, 309.1C, 315.1C, 489C, 523d, 524d, 16223T, 16294G, 16519C & 0 & 2 \\
7 & 73G, 263G, 297G, 315.1C, 489C, 16189C, 16193.1C, 16223T, 16519C, 16527T & 0 & 2 \\
\hline
\end{tabular}

1 patient and 1 control. When these data were included and the McNemar test was repeated to compare the frequency of the M65 haplogroup between patients and controls, the results remained statistically insignificant $(\mathrm{P}=0.1138)$. Haplogroup M30 was present in 2 patients and 7 controls.

Haplotyping. A total of 116 haplotypes, consisting of 7 shared haplotypes and 109 unique haplotypes, were identified in the present study. The haplotypes observed in more than one healthy control or patient are presented in Table VI. Haplotype 4 was exclusively observed in only 4 patients and was not observed in the controls. Another 3 haplotypes (haplotypes 1,6 and 7) were present exclusively in the controls and were not observed in the patients.

\section{Discussion}

A number of previously published studies have investigated the role of mtDNA mutations in the development of diseases, including breast cancer (43-46). Germline and somatic mutations in mtDNA have been studied in breast cancer in various populations across the world $(26,29,30,47)$. Certain studies have suggested a positive correlation between specific D-loop mutations and haplogroups (48-50), and the risk of breast cancer. Therefore, mtDNA may serve as a potential biomarker for the early diagnosis of breast cancer, and its relevance may be dependent on ethnicity $(21,51)$. The present study focussed on identifying germline mutations in the mitochondrial D-loop region and haplogroups in patients with breast cancer and the matched controls to ascertain whether specific mutations and/or haplogroups are associated with sporadic breast cancer in Sri Lankan women of Sinhalese ethnicity.

Whilst a large number of mutations were observed in both the patients and the controls in the present study, there was no significant difference in the prevalence of any of the mutations observed between the patients and the controls. A number of mutations reported to be associated with breast cancer in other populations were observed in the present study $(21,24-26,52,53)$; however, none were exclusive to or more prevalent in the patients with breast cancer. The T16519C mutation, which has been reported to increase the risk of breast cancer among women of European-American ethnicity (25), was present in $84 \%$ of the patients and $82 \%$ of the healthy controls in the present study. Furthermore, the T16189C mutation reported in patients with breast cancer from China, Hong Kong and India $(21,24,26)$ was observed in only 11 patients with breast cancer, but in 17 controls in the present study. T16189C was of particular interest as its occurrence in patients with ductal carcinoma in situ and invasive breast cancer has been previously reported (24). Furthermore, T16189C was identified as a biomarker associated with diabetes (54), which is suggested to contribute to carcinogenesis (55). Ranasinghe et al (28) previously reported that the $\mathrm{T} 16189 \mathrm{C}$ mutation occurs at a prevalence of $16.7 \%$ (10 out of 60) in the general Sinhalese population. The prevalence of the T16189C mutation in the patients in the present study (17.5\%) was consistent with that reported by Ranasinghe et al (28). The T16189C mutation had a comparatively higher prevalence rate (27\%) in the healthy control group in the present study; however, this was not significantly different from the prevalence in the patient cohort. Therefore, in view of the prevalence of the T16189C mutation in the patient cohort in the present study being similar to previous observations in the general population, and not being significantly different to the prevalence in the matched controls, this mutation is unlikely to be associated with the occurrence of breast cancer in Sinhalese women. T16126C, which was reported to be associated with breast cancer negative for hormone receptors (56), was observed in only 1 patient but in 5 controls in the present study. Therefore, the mitochondrial D loop mutations reported to confer an increased risk for breast cancer in other populations failed to show an association with sporadic breast cancer in Sinhalese women. A previous study reported the association of G10398A with breast cancer in the North Indian population (57); however, this variation was not associated with breast cancer risk in Iraqi women (47). Although several novel mitochondrial D-loop mutations were observed in patients in the present study, each of these occurred only in 1 or 2 individuals. The present study eliminated the confounding effect of three important risk factors for breast cancer, namely age, BMI and menopausal status (58). Certain previous studies have controlled for age and sex; however, to the best of our knowledge, none appear to have controlled for BMI or menopausal status $(26,29,30)$. These differences in the study design as well as ethnic differences may account for the lack of an association between any of the D loop mutations with breast cancer in the present study.

The mtDNA haplogroups identified in the present study are in line with the mitochondrial haplogroups reported for 
the Sri Lankan population, where a majority belonged to the $\mathrm{M}$ haplogroup followed by the $\mathrm{N}$ haplogroup and its derivatives (28). Other studies have reported an association between haplogroups and breast cancer, such as haplogroup D5 and $\mathrm{M}$ in the Chinese population $(49,59,60)$ and haplogroup $\mathrm{N}$ in the Indian population $(57,61)$. Whilst the Sinhalese population was not associated with a macro-haplogroup, the haplogroup M65a@16311 was observed in a number of patients and the haplogroup M30 was observed in a number of controls. Although the M65a@16311 haplogroup was more commonly observed in patients than in controls, this difference was not statistically significant.

Haplotype analysis revealed 7 shared haplotypes, although neither the patient cohort nor their controls included family members or known relatives. However, the possibility of having a common ancestor several generations ago among those who shared haplotypes or haplogroups cannot be excluded.

The mtDNA non-coding region serves an important role in the replication of mtDNA as well as in the initiation of transcription (8). Taking these important roles of mtDNA into consideration, the mutations present in each region were analysed. The H-strand origin of replication, the transcription initiation sites for both the $\mathrm{H}$ - and L-strands, as well as associated factor binding sites, such as mtRNAP/TFB2M and TFAM, are located within the non-coding region. Mutational changes within this region could have implications on the replication of mtDNA and transcription of mitochondria-encoded respiration factors. Mutations at two particular sites (57 and 300 ) in the origin of replication on the H-strand were observed only in controls. Nucleotide positions 57 and 300 are hypothesized to be the origins of replication; however, position 191 has been historically used as the origin of replication (62). For comparison, all three sites were analysed as potential origins of H-strand replication. However, there were no common clinical characteristics among the three patients who displayed variations at the $\mathrm{IT}_{\mathrm{H} 1}$ site and the site containing the footprint of mtRNAP/TFB2M binding.

Three conserved sequence blocks (CSB) are located within the mtDNA non-coding region; CSB I (nucleotide 213-233), CSB II (nucleotide 299-315) and CSB III (nucleotide 345-363). Consistent with previous studies $(25,59)$, CSB I and CSB III showed less variation compared to CSB II in all the patient and control samples. However, CSB II showed variations relating to mutational hotspots at positions 301 (C insertion), 309 (C insertion), 310 ( T >C) and 315 (C insertion and C deletion). This is consistent with previous reports, which indicated that variations primarily occur in CSB II $(26,61,62-65)$ and are associated with errors in transcription (63), which can result in the occurrence or progression of diseases such as cancer (65). In the present study, a higher number of mutations occurring at positions 303-315 were observed in the controls (86 variations) compared with patients (76 variations), contradicting previous reports of mutations within the D310 region being associated with cancer $(26,65,68-70)$.

The haplogroup M65a with an additional mutation at 16311 and mutations at the ori-b site were a weak risk factor and a weak protective factor, respectively, for sporadic breast cancer in the present study. Furthermore, the absence of a link between previously reported mutations and haplogroups with breast cancer risk in the present study highlights the need for exercising caution when using non-localised biomarker panels to assess disease risk in populations. However, the association of previously reported mitochondrial D loop mutations and haplogroups with breast cancer risk in other Sri Lankan ethnic groups cannot be excluded, in view of the ethnic differences in the mtDNA and haplogroups among other ethnicities $(27,28)$. The mutations that showed a weak effect in the present study, and those reported in other studies, need to be further evaluated in larger cohorts and in other ethnic groups before their use as predictive biomarkers can be recommended.

\section{Acknowledgements}

We would like to acknowledge the assistance provided by Ms Neluka C. Perera and ward staff, of the National Cancer Institute, Maharagama, for her assistance in the collection of blood samples and patient data and Ms Anoma Jayasoma, for assistance in ensuring safety and compliance with technical procedures. Furthermore, we would like to thank Ms Lakshika Jayasekera and Ms Yamasinghe for their assistance in collecting patient and control details.

\section{Funding}

The present study was funded by the National Science Foundation of Sri Lanka (grant no. NSF/SCH/2016/04).

\section{Availability of data and materials}

The datasets used and/or analysed during the present study are available from the corresponding author on reasonable request.

\section{Authors' contributions}

JTK performed all the experiments, analyzed and interpreted the data and drafted the manuscript. KHT and RR conceived and designed the study, supervised the molecular studies, contributed to data analysis and interpretation and the revision of the manuscript. CR assisted in obtaining patient and control samples and aided in the analysis of data. KDS provided clinical expertise, recruited the study participants and supervised the acquisition of clinical data. All authors read and approved the final manuscript.

\section{Ethics approval and consent to participate}

The present study was approved by the Ethics Review Committee, Faculty of Medicine, University of Colombo, Sri Lanka (approval no. EC/16/097). Written informed consent was obtained from each patient and the control subjects at the time of recruitment.

\section{Patient consent for publication}

Not applicable.

\section{Competing interests}

The authors declare that they have no competing interests. 


\section{References}

1. World Health Organization: Breast cancer: Prevention and control. <http://www.who.int/cancer/detection/breastcancer/en/index 1.html>. Accessed May 14, 2019. https://www. who.int/cancer/detection/breastcancer/en/index 1.html.

2. National Cancer Control Program (NCCP): 'National Cancer Incidence Data Sri Lanka 2014': <http://www.nccp.health. gov.lk/images/PDF_PUBLICATIONS/Cancer_Incidence_in Sri_Lanka_2014.pdf.> NCCP. Accessed May 14,2019. https:// www.nccp.health.gov.lk/pdf/publications/cancer_incidece/ Cancer_Incidence_in_Sri_Lanka_2014.pdf.

3. Milosevic M, Jankovic D, Milenkovic A and Stojanov D: Early diagnosis and detection of breast cancer. Technol Health Care 26 729-759, 2018

4. Henry NL and Hayes DF: Cancer biomarkers. Mol Oncol 6: 140-146, 2012.

5. National Collaborating Centre for Cancer (UK): Familial breast cancer: Classification and care of people at risk of familial breast cancer and management of breast cancer and related risks in people with a family history of breast cancer, 2013.

6. Honrado E, Benítez J and Palacios J: The molecular pathology of hereditary breast cancer: Genetic testing and therapeutic implications. Mod Pathol 18: 1305-1320, 2005.

7. Apostolou P and Fostira F: Hereditary breast cancer: The era of new susceptibility genes. BioMed Res Int 2013: 747318, 2013

8. Taanman JW: The mitochondrial genome: Structure, transcription, translation and replication. Biochim Biophys Acta 1410: 103-123, 1999.

9. Weerts MJA, Sleijfer S and Martens JWM: The role of mitochondrial DNA in breast tumors. Drug Discov Today 24: 1202-1208, 2019.

10. Tuppen HA, Blakely EL, Turnbull DM and Taylor RW: Mitochondrial DNA mutations and human disease. Biochim Biophys Acta 1797: 113-128, 2010.

11. Clayton DA: Mitochondrial DNA replication: What we know. IUBMB Life 55: 213-217, 2003.

12. Gammage PA and Frezza C: Mitochondrial DNA: The overlooked oncogenome? BMC Biol 17: 53, 2019.

13. Hopkins JF, Sabelnykova VY, Weischenfeldt J, Simon R, Aguiar JA, Alkallas R, Heisler LE, Zhang J, Watson JD, Chua MLK, et al: Mitochondrial mutations drive prostrate cancer aggression. Nat Commun 8: 656, 2017.

14. Bussard KM and Siracusa LD: Understanding mitochondrial polymorphisms in cancer. Cancer Res 77: 6051-6059, 2017.

15. Wallace DC: Mitochondria and cancer: Warburg addressed. Cold Spring Harb Symp Quant Biol 70: 363-374, 2005.

16. Strimbu K and Tavel JA: What are biomarkers? Curr Opin HIV AIDS 5: 463-466, 2010

17. Walsh MF, Nathanson KL, Couch FJ and Offit K: Genomic biomarkers for breast cancer risk. Adv Exp Med Biol 882: 1-32, 2016.

18. Weigel MT and Dowsett M: Current and emerging biomarkers in breast cancer: Prognosis and prediction. Endocr Relat Cancer 17: R245-R262, 2010.

19. Moyer VA; U.S. Preventive Services Task Force: Risk assessment, genetic counselling and genetic testing for BRCA-related cancer in women: US preventative services task force recommendation statement. Ann Internal Med 160: 271-281, 2014. https://annals. org/aim/fullarticle/1791499/risk-assessment-genetic-counselinggenetic-testing-brca-related-cancer-women.

20. Cheang MC, Chia SK, Voduc D, Gao D, Leung S, Snider J, Watson M, Davies S, Bernard PS, Parker JS, et al: Ki67 index, HER2 status and prognosis of patients with Luminal B breast cancer. J Natl Cancer Inst 101: 736-350, 2009.

21. Cai FF, Kohler C, Zhang B, Chen WJ, Barekati Z, Garritsen HS Lenner P, Toniolo P, Zhang JJ and Zhong XY: Mutations of mitochondrial DNA as potential biomarkers in breast cancer. Anticancer Res 31: 4267-4271, 2011.

22. Jakupciak JP, Wang W, Markowitz ME, Ally D, Coble M Srivastava S, Maitra A, Barker PE, Sidransky D and O'Connell CD: Mitochondrial DNA as a cancer biomarker. J Mol Diagn 7: 258-267, 2005.

23. Salgado J, Honorato B and García-Foncillas J: Review: Mitochondrial defects in breast cancer. Clin Med Oncol 2: 199-207, 2008.

24. Wang Y, Liu VW, Tsang PC, Chiu PM, Cheung AN, Khoo US, Nagley P and Ngan HY: Microsatelite instability in mitochondrial genome of common female cancers. Int J Gynecol Cancer 1 (Suppl 16): S259-S266, 2006
25. Bai RK, Leal SM, Covarrubias D, Liu A and Wong LJ: Mitochondrial genetic background modifies breast cancer risk. Cancer Res 67: 4687-4694, 2007.

26. Tipirisetti NR, Govatati S, Pullari P, Malempati S, Thupurani MK, Perugu S, Guruvaiah P, Rao KL, Digumarti RR, Nallanchakravarthula $\mathrm{V}$, et al: Mitochondrial control region alterations and breast cancer risk: A study in South Indian population. PLoS One 9: e85363, 2014.

27. Ranaweera L, Kaewsutthi S, Win Tun A, Boonyarit H, Poolsuwan S and Lertrit P: Mitochondrial DNA history of Sri Lankan ethnic people: Their relations within the island and with the Indian sub-continental populations. J Hum Genet 59: 28-36, 2014.

28. Ranasinghe R, Tennekoon KH, Karunanayake EH, Lembring M and Allen M: A study of genetic polymorphisms in mitochondrial DNA hypervariable regions I and II of the five major ethnic groups and Vedda population in Sri Lanka. Leg Med (Tokyo) 17: 539-546, 2015.

29. Rahmani B, Azimi C, Omranipour R, Raoofian R, Zendehdel K, Saee-Rad S and Heidari M: Mutation screening in the mitochondrial D-loop region of tumoral and non-tumoral breast cancer in Iranian patients. Acta Med Iran 50: 447-453, 2012

30. Sultana GN, Rahman A, Shahinuzzaman AD, Begum RA and Hossain CF: Mitochondrial DNA mutations-candidate biomarkers for breast cancer diagnosis in Bangladesh. Chin J Cancer 31: 449-454, 2012

31. Miller SA, Dykes DD and Polesky HF: A simple salting out procedure for extracting DNA from human nucleated cells. Nucleic Acids Res 16: 1215, 1988.

32. Rieder MJ, Taylor SL, Tobe VO and Nickerson DA: Automating the identification of DNA variations using quality-based fluorescence re-sequencing: Analysis of the human mitochondrial genome. Nucleic Acids Res 26: 967-973, 1998.

33. Behar DM, van Oven M, Rosset S, Metspalu M, Loogvali EL, Silva NM, Kivisild T, Torroni A and Villems R: A Copernican reassessment of human mitochondrial DNA tree from its root. Am J Hum Genet 90: 675-684, 2012.

34. Ranasinghe R: Mitochondrial DNA analysis, haplotype and haplogroup determination and inference of maternal lineage in five major ethnic groups and Vedda population in Sri Lanka (dissertation). Institute of Biochemistry, Molecular Biology and Biotechnology, University of Colombo, 2016

35. Kloss-Brandstätter A, Pacher D, Schönherr S, Weissensteiner H, Binna R, Specht G and Kronenberg F: HaploGrep: A fast and reliable algorithm for automatic classification of mitochondrial DNA haplogroups. Hum Mutat 32: 25-32, 2011.

36. Parson $\mathrm{W}$ and Dur A: EMPOP-a forensic mtDNA database. Forensic Sci Int Genet 1: 88-92, 2007

37. van Oven M and Kayser M: Updated comprehensive phylogenetic tree of global human mitochondrial DNA variation. Hum Mutat 30: E386-E394, 2009.

38. GraphPad QuickCalcs: McNemar test to analyse a matched case-control study. https://www.graphpad.com/quickcalcs/McNemar1.cfm. Accessed August 1, 2019. https://www. graphpad.com/quickcalcs/mcNemar1.

39. Elston CW and Ellis IO: Pathological prognostic factors in breast cancer. I. The value of histological grade in breast cancer: Experience from a large study with long term follow up. Histopathology 19: 403-410, 1991

40. Stoneking M: Hypervariable sites in the mtDNA control region are mutational hotspots. Am J Hum Genet 67: 1029-1032, 2000.

41. Falkenberg M: Mitochondrial DNA replication in mammalian cells: Overview of the pathway. Essays Biochem 62: 287-296, 2018.

42. Morozov YI and Temiakov D: Human mitochondrial transcription initiation complexes have similar topology on the light and heavy strand promoters. J Biol Chem 291: 13432-13435, 2016

43. Zhu W, Qin W, Bradley P, Wessel A, Puckett CL and Sauter ER: Mitochondrial DNA mutations in breast cancer tissue and in matched nipple aspirate fluid. Carcinogenesis 26: 145-152, 2005.

44. Covarrubias D, Bai RK, Wong LC and Leal SM: Mitochondrial DNA variant interactions modify breast cancer risk. J Hum Genet 53: 924-928, 2008 .

45. Schon EA, DiMauro S and Hirano M: Human mitochondrial DNA: Roles of inherited and somatic mutations. Nat Rev Genet 13: 878-890, 2012.

46. Hertweck KL and Dasgupta S: The landscape of mtDNA modifications in cancer: A tale of two cities. Front Oncol 7: 262, 2017.

47. Ismaeel HM, Younan HQ and Zahid RA: Mitochondrial DNA A10398G mutation is not associated with breast cancer risk in a sample of Iraqi women. Curr Res J Biol Sci 5: 126-129, 2013. 
48. Yadav N and Chandra D: Mitochondrial DNA mutations and breast tumorigenesis. Biochim Biophys Acta 1836: 336-344, 2013.

49. Ma L, Fu Q, Xu B, Zhou H, Gao J, Shao X, Xiong J, Gu Q, Wen S, Li F, et al: Breast cancer-associated mitochondrial DNA haplogroup promotes neoplastic growth via ROS-mediated AKT activation. Int J Cancer 142: 1786-1796, 2018.

50. Riley V, Erzurumluoglu AM, Rodriguez S and Bonilla C: Mitochondrial DNA haplogroups and breast cancer risk factors in the avon longitudinal study of parents and children (ALSPAC). Genes (Basel) 9: E395, 2018.

51. Yu M: Circulating cell-free mitochondrial DNA as a cancer biomarker: Opportunities and challenges. Mitochondrial DNA 23: 329-332, 2012.

52. Czarnecka AM, Krawczyk T, Plak K, Klemba A, Zdrozny M, Arnold RS, Kofler B, Golik P, Szybinska A, Lubinski J, et al: Mitochondrial genotype and breast cancer predisposition. Oncol Rep 24: 1521-1534, 2010.

53. Tan DJ, Bai RK and Wong LJ: Comprehensive scanning of somatic mitochondrial DNA mutations in breast cancer. Cancer Res 62: 972-976, 2002.

54. Poulton J, Luan J, Macaulay V, Hennings S, Mitchell J and Wareham NJ: Type 2 diabetes is associated with a common mitochondrial variant: Evidence from a population-based case-control study. Hum Mol Genet 11: 1581-1583, 2002.

55. Giovannucci E, Harlan DM, Archer MC, Bergenstal RM, Gapstur SM, Habel LA, Pollak M, Regensteiner JG and Yee D: Diabetes and cancer: A consensus report. Diabetes Care 33: $1674-1685,2010$.

56. Tommasi S, Favia P, Weigl S, Bianco A, Pilato B, Russo L, Paradiso A and Petruzzella V: Mitochondrial DNA variants and risk of familial breast cancer: An exploratory study. Int J Oncol 44: 1691-1698, 2014

57. Darvishi K, Sharma S, Bhat AK, Rai E and Bamezai RN Mitochondrial DNA G10398A polymorphism imparts maternal Haplogroup $\mathrm{N}$ a risk for breast and esophageal cancer. Cancer Lett 249: 249-255, 2007.

58. Rojas K and Stuckey A: Breast cancer epidemiology and risk factors. Clin Obstet Gynecol 59: 651-672, 2016.

59. Shen L, Wei J, Chen T, He J, Qu J, He X, Jiang L, Qu Y, Fang H, Chen G, et al: Evaluating mitochondrial DNA in patients with breast cancer and benign breast disease. J Cancer Res Clin Oncol 137: 669-675, 2011.
60. Fang H, Shen L, Chen T, He J, Ding Z, Wei J, Qu J, Chen G, $\mathrm{Lu} \mathbf{J}$ and Bai Y: Cancer type-specific modulation of mitochondrial haplogroups in breast, colorectal and thyroid cancer. BMC Cancer 10: 421, 2010.

61. Gochhait S, Bhatt A, Sharma S, Singh YP, Gupta P and Bamezai RN: Concomitant presence of mutations in mitochondrial genome and p53 in cancer development-a study in north Indian sporadic breast and esophageal cancer patients. Int J Cancer 123: 2580-2586, 2008.

62. Holt IJ and Reyes A: Human mitochondrial DNA replication. Cold Spring Harb Perspect Biol 4: a012971, 2012.

63. Tan BG, Wellesley FC, Savery NJ and Szczelkun MD: Length heterogeneity at conserved sequence block 2 in human mitochondrial DNA acts as a rheostat for RNA polymerase POLRMT activity. Nucleic Acids Res 44: 7817-7829, 2016.

64. Chatterjee A, Mambo E and Sidransky D: Mitochondrial DNA mutations in human cancer. Oncogene 25: 4663-4674, 2006.

65. Xu C, Tran-Thanh D, Ma C, May K, Jung J, Vecchiarelli J and Done SJ: Mitochondrial D310 mutation in the early development of breast cancer. Br J Cancer 106: 1506-1511, 2012.

66. Aral C, Kaya H, Ataizi-Celikel C, Akkiprik M, Sonmez O, Gulluoglu BM and Ozer A: A novel approach for rapid screening of mitochondrial D310 polymorphism. BMC Cancer 6: 21, 2006.

67. Agaronyan K, Morozov YI, Anikin M and Temiakov D: Replication-transcription switch in human mitochondria. Science 347: 548-551, 2015.

68. Jiménez-Morales S, Pérez-Amado CJ, Langley E and Hidalgo-Miranda A: Overview of mitochondrial germline variants and mutations in human disease: Focus on breast cancer (Review). Int J Oncol 53: 923-936, 2018.

69. Alhomidi MA, Vedicherla B, Movva S, Rao PK, Ahuja YR and Hasan Q: Mitochondrial D310 instability in Asian Indian breast cancer patients. Tumour Biol 34: 2427-2432, 2013

70. ParrellaP,SeripaD,Matera MG, Rabitti C,Rinaldi M,MazzarelliP Gravina C, Gallucci M, Altomare V, Flammia G, et al: Mutations of the D310 mitochondrial mononucleotide repeat in primary tumors and cytological specimens. Cancer Lett 190: 73-77, 2003. 